\title{
Small-scale spatial analysis of intermediate and definitive hosts of Angiostrongylus cantonensis
}

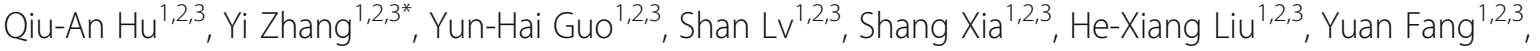 \\ Qin Liu ${ }^{1,2,3}$, Dan Zhu' ${ }^{1,2,3}$, Qi-Ming Zhang ${ }^{4}$, Chun-Li Yang ${ }^{1,2,3}$ and Guang-Yi Lin ${ }^{5}$
}

\begin{abstract}
Background: Angiostrongyliasis is a food-borne parasitic zoonosis. Human infection is caused by infection with the third-stage larvae of Angiostrongylus cantonensis. The life cycle of A. cantonensis involves rodents as definitive hosts and molluscs as intermediate hosts. This study aims to investigate on the infection status and characteristics of spatial distribution of these hosts, which are key components in the strategy for the prevention and control of angiostrongyliasis.

Methods: Three villages from Nanao Island, Guangdong Province, China, were chosen as study area by stratified random sampling. The density and natural infection of Pomacea canaliculata and various rat species were surveyed every three months from December 2015 to September 2016, with spatial correlations of the positive $P$. canaliculata and the infection rates analysed by ArcGIS, scan statistics, ordinary least squares (OLS) and geographically weighted regression (GWR) models.

Results: A total of 2192 P. canaliculata specimens were collected from the field, of which 1190 were randomly chosen to be examined for third-stage larvae of $A$. cantonensis. Seventy-two Angiostrongylus-infected snails were found, which represents a larval infection rate of $6.1 \%$ (72/1190). In total, 110 rats including 85 Rattus norvegicus, $10 R$. flavipectus, one $R$. losea and 14 Suncus murinus were captured, and 32 individuals were positive (for adult worms), representing an infection rate of $29.1 \%$ of the definitive hosts (32/110). Worms were only found in $R$. norvegicus and $R$. flavipectus, representing a prevalence of 36.5\% (31/85) and 10\% (1/10), respectively in these species, but none in $R$. losea and S. murinus, despite testing as many as 32 of the latter species. Statistically, spatial correlation and spatial clusters in the spatial distribution of positive $P$. canaliculata and positive rats existed. Most of the spatial variability of the host infection rates came from spatial autocorrelation. Nine spatial clusters with respect to positive $P$. canaliculata were identified, but only two correlated to infection rates. The results show that corrected Akaike information criterion, $R^{2}, R^{2}$ adjusted and $\sigma^{2}$ in the GWR model were superior to those in the OLS model.

Conclusions: P. canaliculata and rats were widely distributed in Nanao Island and positive infection has also been found in the hosts, demonstrating that there was a risk of angiostrongyliasis in this region of China. The distribution of positive P. canaliculata and rats exhibited spatial correlation, and the GWR model had advantage over the OLS model in the spatial analysis of hosts of $A$. cantonensis.
\end{abstract}

Keywords: Angiostrongylus cantonensis, Snail intermediate host, Pomacea canaliculata, Rat definitive host, Spatial analysis

\footnotetext{
*Correspondence: zhang1972003@163.com

'National Institute of Parasitic Diseases, Chinese Center for Disease Control and Prevention; Chinese Center for Tropical Diseases Research, Shanghai 200025, China

${ }^{2}$ WHO Collaborating Centre for Tropical Diseases; National Center for International Research on Tropical Diseases, Ministry of Science and Technology, Shanghai 200025, China

Full list of author information is available at the end of the article
}

(c) The Author(s). 2018 Open Access This article is distributed under the terms of the Creative Commons Attribution 4.0 International License (http://creativecommons.org/licenses/by/4.0/), which permits unrestricted use, distribution, and reproduction in any medium, provided you give appropriate credit to the original author(s) and the source, provide a link to the Creative Commons license, and indicate if changes were made. The Creative Commons Public Domain Dedication waiver (http://creativecommons.org/publicdomain/zero/1.0/) applies to the data made available in this article, unless otherwise stated. 


\section{Multilingual absracts}

Please see Additional file 1 for translations of the abstract into the five official working languages of the United Nations.

\section{Background}

Angiostrongyliasis is a food-borne parasitic zoonosis while human infection is caused by infection with the third-stage larvae of Angiostrongylus cantonensis. The life cycle of $A$. cantonensis involves rodents as definitive hosts and molluscs as intermediate hosts [1]. Humans are dead-end hosts for A. cantonensis, and they can still be infected through ingestion of infected molluscs, contaminated vegetables, or transport hosts, such as shrimps, crabs, frogs and lizards [2]. Infected individuals present with eosinophilic meningitis or meningoencephalitis [3]. More than 30 recent outbreaks have been reported in mainland China so far [4-7]. Human infection is listed as an emerging food-borne parasitic disease by the World Health Organization (WHO) and is classified as an emerging infectious disease by the Chinese Ministry of Health since $2003[6,8,9]$.

Previously, studies on angiostrongyliasis were mainly concentrated on epidemic foci and case descriptions. Most reports were based on descriptive epidemiological methods in general, while the spatial parameters were seldom considered [10]. In recent years, spatial analysis using the geographic information system (GIS) has started to be applied more widely in the field of parasitic diseases [11, 12]. From then on, recent such work on schistosomiasis and malaria at different scales has provided new ideas and methods for angiostrongyliasis research. It would be therefore important to know the spatial distribution, infection status, and the factors that influence these parameters both for snail intermediate hosts and for rat definitive hosts. Such knowledge would be most useful for the prevention and control of angiostrongyliasis and estimating risk of infection. This study aimed at analysing the characteristics of spatial distribution of these two hosts at village scale, by exploring the applicability of ordinary least squares regression (OLS) and geographically weighted regression (GWR) models to provide a methodology reference and theoretical basis for the prevention and control of this emerging human parasitic disease.

\section{Methods \\ Study area}

Nanao Island is located at the extreme eastern edge $\left(116^{\circ} 53^{\prime}-117^{\circ} 19^{\prime} \mathrm{E}, \quad 23^{\circ} 11^{\prime}-23^{\circ} 32^{\prime} \mathrm{N}\right)$ of Guangdong Province, China (see Fig. 1). The annual average temperature is $21.5^{\circ} \mathrm{C}$ and the annual average rainfall is $1348 \mathrm{~mm}$. The snail intermediate host Pomacea canaliculata and various

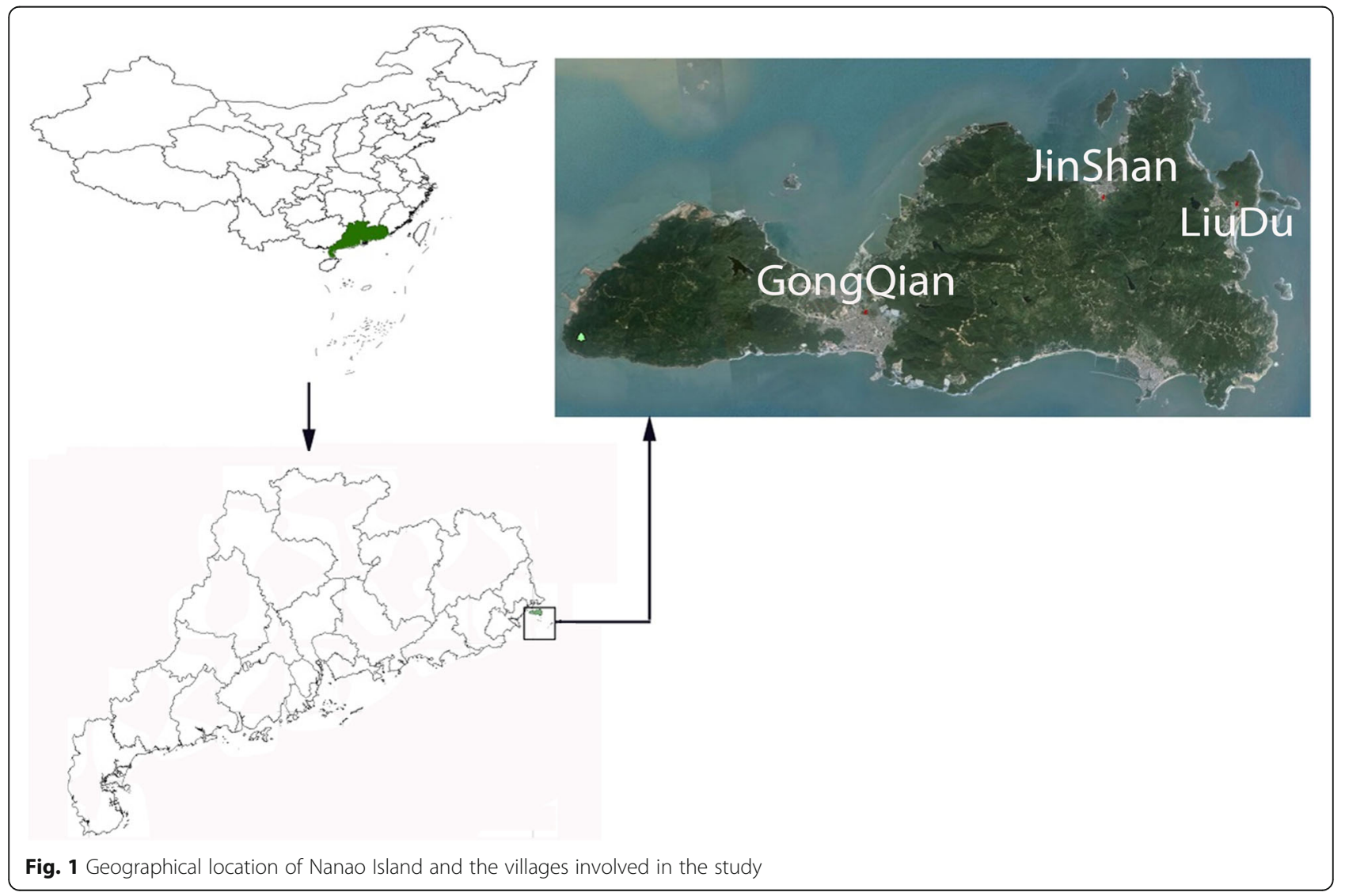




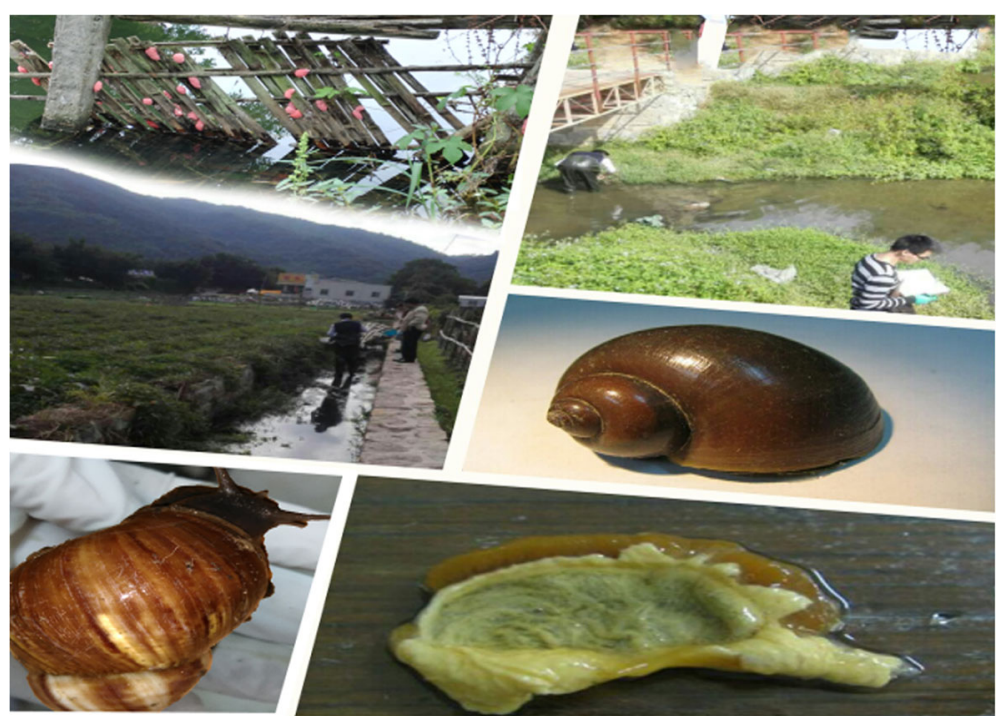

Fig. 2 Collection of snails and screening of Angiostrongylus cantonensis

rat definitive hosts of $A$. cantonensis are widely distributed on the island. Besides, from previous research data, there have been revelations that there might be hotspots of A. cantonensis infections in this region of China $[13,14]$.

\section{Data collection}

Three villages on Nanao Island (Gongqian Village, Liudu Village and Jinshan Village) belonging to the towns of Houzhai, Shenao and Yunao, respectively, were selected as study areas for stratified random sampling. The density and infection status of $P$. canaliculata and various rat species were surveyed every three months from December 2015 to September 2016. The method of trapping rats was referred to sampling procedure of vector infected by pathogens - Rodent (GB/T28940-2012 China). In addition, environmental data, such as season, environmental type, distance from residential areas and fresh-water relation were also collected. The geographical coordinates for each sampling point were recorded by a Garmin 60CS (Garmin Corp., Olathe, KS, USA) global positioning system (GPS) instrument.

Pomacea canaliculata lung and muscles were examined for third-stage larvae by lung-microscopy, tissue homogenate and enzyme digestion [15]. Rats were captured by night feeding and trapping, and were drowned and dissected with hearts and lungs checked for adult worms. Morphological observation was performed for $P$. canaliculata, rats and third-stage larvae of $A$. cantonensis, followed by DNA extraction and polymerase chain reaction to double-check the species. A unique identification number for every sampling site, including spatial data, density and natural infection rate, was established to reflect the distribution and infection status of these hosts.

\section{Statistical analysis \\ Descriptive analysis}

Infection rates and densities of snails and rats were analysed by non-parametric rank and summing tests using the statistical software SAS 9.3 (SAS Institute, Cary NC, USA) and the Chi-square test (Fisher's exact test). The correlation between density and infection rate was analysed by Spearman's rank correlation. The level of $P<0.05$ (with two-tailed test) was chosen for statistical significance.

\section{Spatial correlation analysis}

ArcGIS (version 10.2, ESRI Corp., Redlands, CA, USA) was used to analyse the spatial correlation of the

Table 1 Summary of the investigations on the snail intermediate hosts

\begin{tabular}{llllll}
\hline Sampling village & Number of collected snails & Number of examined snails & Number of infected snails & Density $\left(\right.$ number $\left./ \mathrm{m}^{2}\right)$ & Infection rate $(\%)$ \\
\hline Gongqian & 644 & 283 & 9 & 8.00 & 3.18 \\
Liudu & 886 & 486 & 24 & 9.92 & 4.94 \\
Jinshan & 662 & 421 & 39 & 3.54 & 9.26 \\
Total & 2192 & 1190 & 72 & 6.66 & 6.05 \\
\hline
\end{tabular}



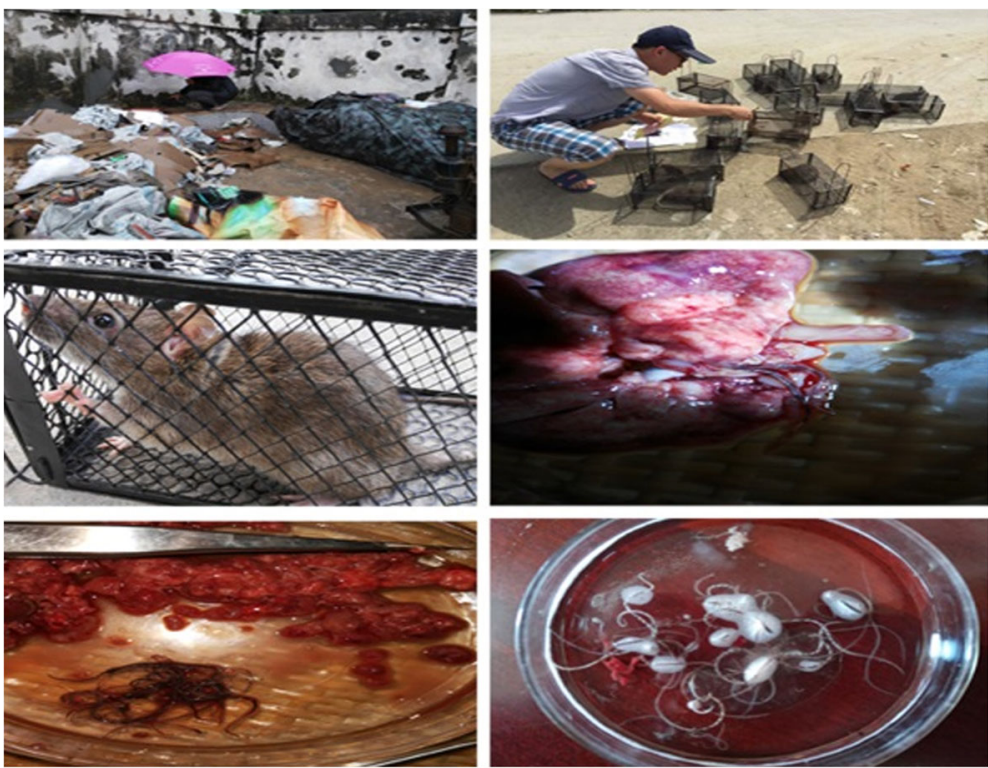

Fig. 3 Capture of rats and screening of Angiostrongylus cantonensis

infection rates, both for snails and for rats, by establishing a semivariogram model, which provides the measure of variance as a function of distance between data points. The semivariance graph conveyed information about the continuity and spatial variability of the process $[16,17]$ :

$$
\mathrm{r}(h)=\frac{1}{2 N(h)} \sum_{i=1}^{N(h)}\left[Z\left(x_{i}\right)-Z\left(x_{i}+h\right)\right]^{2} .
$$

In the formula, $\mathrm{Z}\left(x_{i}\right)$ and $Z\left(x_{i}+h\right)$ are sample values at locations $x_{i}$ and $\left(x_{i}+h\right), N(h)$ the number of paired data at the distance $h$ (points with $h$ separation distance), and $\mathrm{r}(\mathrm{h})$ the semivariance. The value of the semivariogram model is based on the fixed distance $h$. The model includes the following four parameters: Nugget, Range, Sill and Partial Sill. The degree of spatial autocorrelation is reflected by the ratio between Partial Sill and Sill; the greater the ratio, the stronger the spatial autocorrelation. The ratio between Nugget and Sill is called the substrate effect, which represents the variation among samples and is caused by a random factor.

\section{Scan statistics}

SaTScan 9.4 (https://www.satscan.org/) was used to detect spatial aggregation of infection rates. The parameters were set as Poisson distribution model and $30 \%$ of the population at risk as maximum spatial cluster size. Monte Carlo simulation was used to find the likelihood ratio (LLR) and to explore the maximum possible cluster [18-20].

\section{Spatial modelling}

The OLS and GWR models were compared with respect to their ability to analyse the relationship between season, type of environment, distance from residential areas and density on the one hand, and the spatial distribution of infection rates (both in the snail and in the rat definitive hosts) on the other hand. This was performed by using the Geostatistical Analyst tool in ArcGIS by comparing the degree of fit.

The OLS model is a global spatial analytical method where the basic assumption is that the dependent and independent variables have the same linear relations in

Table 2 Summary of the investigations on the rat definitive hosts

\begin{tabular}{llllll}
\hline Sampling village & Number of mouse cages & Number of captured rats & Number of infected rats & Density (number/cage) & Infection rate (\%) \\
\hline Gongqian & 289 & 71 & 29 & 0.25 & 40.85 \\
Liudu & 117 & 13 & 2 & 0.11 & 15.38 \\
Jinshan & 130 & 26 & 1 & 0.20 & 3.85 \\
Total & 536 & 110 & 32 & 0.21 & 29.09 \\
\hline
\end{tabular}




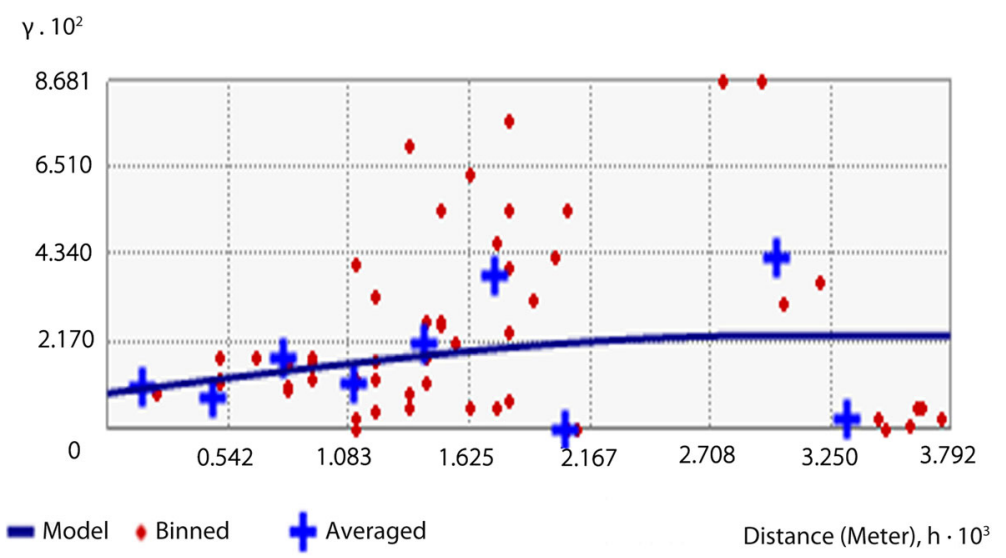

Fig. 4 Semivariogram of infection rate of Angiostrongylus cantonensis in Pomacea canaliculata

all spatial parts of the area studied, i.e. its parameters are constant in different locations. Therefore, OLS can only produce average and global parameter estimates, rather than local ones [21]. The OLS model was calculated as follows:

$$
y_{i}=\beta_{0}+\sum_{j=1}^{n} \beta_{j} X_{i j}+\varepsilon_{i}
$$

Where $y_{i}$ is the value at the $i^{\text {th }}$ region, $I=1,2 \ldots \mathrm{N}, X_{i j}$ the $j^{\text {th }}$ variable value at the $i^{\text {th }}$ region, and $\varepsilon_{i}$ the linear random error.

The GWR model is a local spatial analytical method, which is mainly used in non-stationary parameter estimation for the analysis of local spatial relation. Its parameters can change with different geographic positions. Since both spatial autocorrelation and spatial heterogeneity are taken into account in the GWR model, it has more value in the choice of spatial influence factors of disease compared with the general spatial models, such as OLS, spatial lag model, spatial error model and spatial Durbin model [22-24]. The GWR model was calculated as follows:

$$
Y_{i}=\beta_{0}\left(u_{i}, v_{i}\right)+\sum_{j=1}^{k} \beta_{j}\left(u_{i}, v_{i}\right) X_{i j}+\varepsilon_{i}
$$

where the term $\left(u_{i}, v_{i}\right)$ is the geographic coordinates of the $i^{\text {th }}$ sample, $\beta_{j}$ the regression coefficient that changes with geographic position, and $\varepsilon_{i}$ the linear random error.

\section{Results}

\section{Descriptive analysis}

A total of 2192 P. canaliculata snails were collected from the three study villages (see Fig. 2). About half of the sails (1190) were randomly chosen to be microscopically examined, which resulted in $72(6.1 \%)$ positives (see Table 1 ). When comparing according to the study sites, it was found that the difference in infection rates between the villages was statistically significant $\left(\chi^{2}=12.8058, P=0.0017\right)$. The infection rates between Gongqian Village and Jinshan Village were statistically significant $\left(\chi^{2}=9.8581, P=0.0017\right)$,

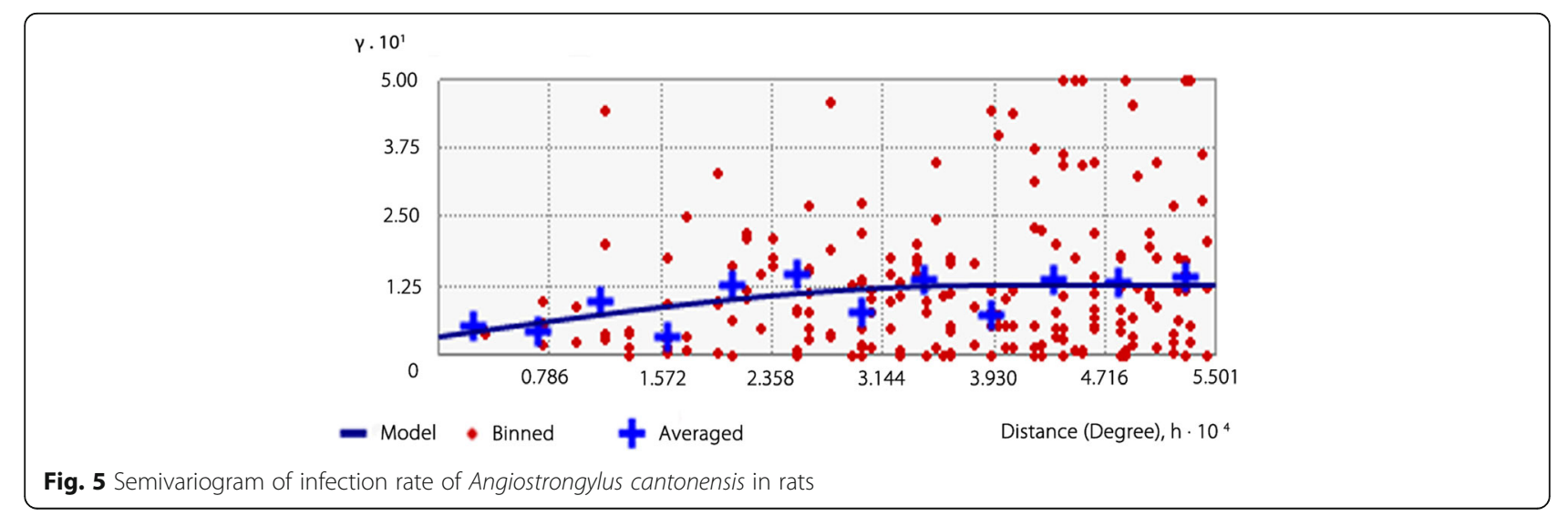


Table 3 Scanning of Angiostrongylus cantonensis infection rate in Pomacea canaliculata

\begin{tabular}{|c|c|c|c|c|c|c|c|}
\hline $\begin{array}{l}\text { Cluster } \\
\text { ID }\end{array}$ & $\begin{array}{l}\text { Cluster } \\
\text { centre }\end{array}$ & $\begin{array}{l}\text { Radius } \\
(\mathrm{m})\end{array}$ & $\begin{array}{l}\text { Population } \\
\text { (number) }\end{array}$ & $\begin{array}{l}\text { Positives } \\
\text { (number) }\end{array}$ & $\mathrm{RR}$ & LLR & $P$-value \\
\hline 1 & $23.454220 \mathrm{~N}, 117.094280 \mathrm{E}$ & 49 & 59 & 18 & 6.39 & 16.33 & 0.000 \\
\hline 2 & $23.447210 \mathrm{~N}, 117.127850 \mathrm{E}$ & 2.4 & 53 & 12 & 4.29 & 7.63 & 0.003 \\
\hline 3 & $23.454330 \mathrm{~N}, 117.100740 \mathrm{E}$ & - & 12 & 5 & 7.33 & 5.51 & 0.033 \\
\hline 4 & $23.429340 \mathrm{~N}, 117.027880 \mathrm{E}$ & - & 29 & 6 & 3.64 & 3.26 & 0.300 \\
\hline 5 & $23.453960 \mathrm{~N}, 117.092300 \mathrm{E}$ & - & 8 & 3 & 6.42 & 3.00 & 0.368 \\
\hline 6 & $23.455660 \mathrm{~N}, 117.099530 \mathrm{E}$ & - & 23 & 4 & 2.98 & 1.66 & 0.893 \\
\hline 7 & $23.455690 \mathrm{~N}, 117.101070 \mathrm{E}$ & - & 26 & 4 & 2.63 & 1.35 & 0.954 \\
\hline 8 & $23.448060 \mathrm{~N}, 117.127360 \mathrm{E}$ & 7.1 & 61 & 7 & 1.99 & 1.25 & 0.970 \\
\hline 9 & $23.448060 \mathrm{~N}, 117.127360 \mathrm{E}$ & - & 33 & 4 & 2.06 & 0.81 & 0.998 \\
\hline
\end{tabular}

RR Relative risk, LLR Log likelihood ratio

as well as between Liudu Village and Jinshan Village $\left(X^{2}=6.5297, P=0.0106\right)$. However, the infection rates were not statistically significant $\left(\chi^{2}=1.3459, P=0.2460\right)$ between Gongqian Village and Liudu Village.

A total of 110 rats were captured, including $R$. norvegicus, R. flavipectus (see Fig. 3), Rattus losea and Suncus murinus, of which 32 (29.1\%) were positive (see Table 2). There were 31 positive $R$. norvegicus and only one $R$. flavipectus, but no adult worms at all were found in $R$. losea and S. murinus. The variation of infection rate between different species of rodents was significant (Fisher's Exact Test, $P=0.0051$ ), and there was also a significant variation of the infection rate of rodents between the villages $\left(\chi^{2}=13.9719\right.$, $P=0.0009)$. The infection rates between Gongqian Village and Jinshan Village were statistically significant $\left(X^{2}=12.1951, P=0.0005\right)$. However, the infection rates between Gongqian Village and Liudu Village $\left(\chi^{2}=3.0590\right.$, $P=0.0803$ ), as well as between Liudu Village and Jinshan Village $\left(X^{2}=1.6250, P=0.2024\right)$ were not statistically significant.

The Spearman's rank correlation tests showed that no statistically significant correlation was observed between $P$. canaliculata densities and infection rates $\left(\mathrm{r}_{\mathrm{s}}=0.20582\right.$, $P=0.2151$ ), but the correlation between these parameters in the rats was significant $\left(\mathrm{r}_{\mathrm{s}}=0.51755, P \leq 0.0001\right)$.

\section{Spatial autocorrelation}

The semivariance model for infection rate of $P$. canaliculata (see Fig. 4), was:

$$
\mathrm{r}(h)=0.008833^{*} \text { Nugget }+0.014418^{*} \text { Spherical }(0.0030444) .
$$

In this model, the values of Nugget, Partial Sill and Sill were $0.008833,0.014418$ and 0.023251 , respectively. The ratio of Nugget to Sill was $38 \%$ and the ratio of partial Sill to Sill was $62 \%$, which indicated that the spatial heterogeneity was mainly caused by spatial autocorrelation.

The semivariance model for the infection rate of rats (see Fig. 5), was:

$$
r(h)=0.032829^{*} \text { Nugget }+0.093567^{*} \text { Spherical }(0.00038847) .
$$

Here, the value of Nugget, Partial Sill and Sill were $0.032829,0.093567$ and 0.093567 , respectively. The ratio of Nugget to Sill was $26 \%$ and the ratio of partial Sill to Sill was $74 \%$, which also indicated that the spatial heterogeneity was mainly caused by spatial autocorrelation.

\section{Spatial scan statistics}

As shown in Tables 3 and 4, eleven spatial clusters were detected: nine clusters of infected snails and two of infected rats. The maximum radius of accumulation areas in the infection rates of $P$. canaliculata and rats were $0.049 \mathrm{~km}$ and $0.069 \mathrm{~km}$, respectively.

Spatial cluster areas and the sampling sites were added to Remote Sensing maps from Google Earth for spatial overlay analysis. The infected snail clusters were mostly seen in artificial channels near the villages, while the infected rat clusters were found in places characterized by

\begin{tabular}{|c|c|c|c|c|c|c|c|}
\hline Cluster ID & $\begin{array}{l}\text { Cluster } \\
\text { centre }\end{array}$ & $\begin{array}{l}\text { Radius } \\
\text { (m) }\end{array}$ & $\begin{array}{l}\text { Population } \\
\text { (number) }\end{array}$ & $\begin{array}{l}\text { Positives } \\
\text { (number) }\end{array}$ & $\mathrm{RR}$ & LLR & $P$-value \\
\hline 1 & $23.429990 \mathrm{~N}, 117.026060 \mathrm{E}$ & 36 & 23 & 13 & 2.59 & 3.19 & 0.279 \\
\hline 2 & $23.430870 \mathrm{~N}, 117.025420 \mathrm{E}$ & 69 & 27 & 12 & 1.84 & 1.32 & 0.955 \\
\hline
\end{tabular}

Table 4 Scanning of Angiostrongylus cantonensis infection rate in rats 


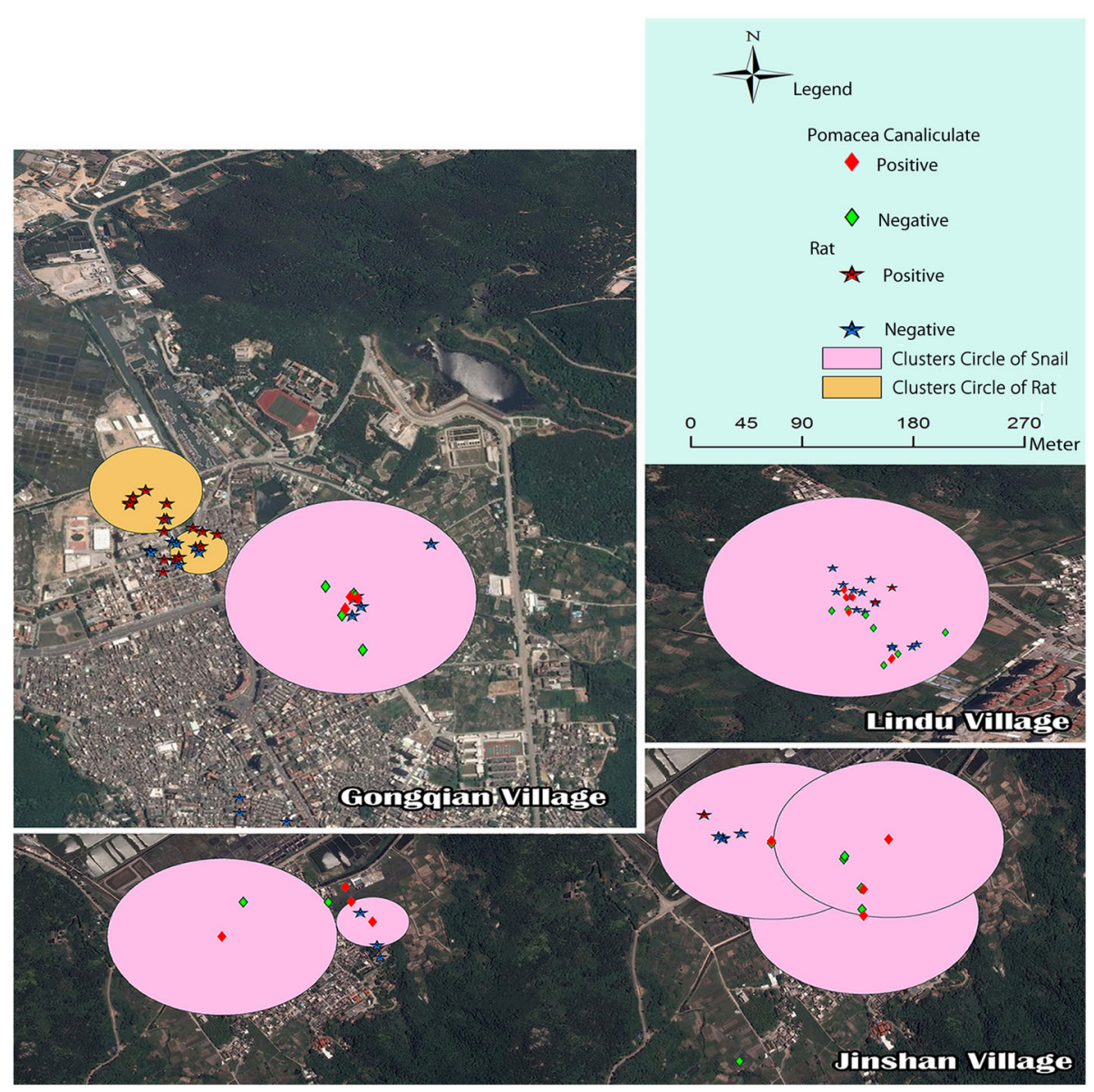

Fig. 6 An overview of the sampling site and cluster areas of positive samples

the presence of messy environment, such as rubbish heaps and recycling centres (see Fig. 6).

\section{Spatial modelling}

First, the OLS model was selected to find the associations with the variables chosen and then the modelling was performed to decide whether the GWR model was also needed. The parameters and the fitting criterion of OLS model were obtained (see Table 5 and Table 6).

With the aim to analyse the residual error in the OLS model of the $P$. canaliculata infection rate and that of the rats, Jarque-Bera statistic (JB) was instituted. JB for $P$. canaliculata infection rate was $13.013(P=0.0015)$, and that of the rats $21.627(P=0.00002)$. They were obviously both statistically significant, which indicates that the residual error did not fit the hypothesis of normal distribution, i.e. data on the infection rate was non-stationary in space and there was spatial heterogeneity. This means that spatial information was not fully extracted by the OLS model.

It is important to set the weighting when GWR model was established. In order to make sure of the

Table 5 Infection rates of Pomacea canaliculata with Angiostrongylus cantonensis using different variables estimated by OLS approach

\begin{tabular}{lllllllll}
\hline Variable & Coefficient & SE & $T$ & $P$ & Robust_SE & Robust_T & Robust_P & VIF \\
\hline Intercept & 6.8602 & 8.1193 & 0.8449 & 0.4042 & 6.0446 & 1.1349 & 0.2646 & - \\
Season & 0.7449 & 0.5753 & 1.2948 & 0.2044 & 0.5014 & 1.4856 & 0.1469 \\
Environment & -0.2110 & 1.9554 & -0.1079 & 0.9148 & 1.7820 & -0.1184 & 0.9067 & 1.0257 \\
Distance & -2.7890 & 2.2998 & -1.2127 & 0.2339 & 1.9624 & -1.4213 & 0.1646 & 1.0222 \\
Density & 0.1857 & 0.3042 & 0.6104 & 0.5458 & 0.2584 & 0.7185 & 0.4775 & 1.0614 \\
\hline
\end{tabular}

$A I C=306.0523, A / C_{C}=308.7620, R^{2}=0.0864, R^{2}$ adjusted $=0.0243, \sigma^{2}=154.6894$

OLS Ordinary least squares, SE Standard error, VIF Variance inflation factor 
Table 6 Infection rates of rats with Angiostrongylus cantonensis using different variables estimated by OLS approach

\begin{tabular}{lllllllll}
\hline Variable & Coefficient & SE & $T$ & $P$ & Robust_SE & Robust_T & Robust_P & VIF \\
\hline Intercept & -16.6792 & 16.3587 & -1.0196 & 0.3128 & 10.3744 & -1.6078 & 0.1142 & - \\
Season & 1.7161 & 1.4141 & 1.2136 & 0.2306 & 1.3195 & 1.3006 & 0.1994 & 1.3183 \\
Environment & 6.3547 & 3.9842 & 1.5950 & 0.1170 & 3.6805 & 1.7266 & 0.0904 & 1.1972 \\
Distance & -3.1430 & 5.8266 & -0.5394 & 0.5920 & 3.1362 & -1.0022 & 0.3210 & 1.1584 \\
Density & 61.0019 & 25.8755 & 2.3575 & $0.0224^{*}$ & 25.5840 & 2.3844 & $0.0209^{*}$ & 1.3275 \\
\hline
\end{tabular}

$A I C=529.8539, A / C_{C}=531.6039, R^{2}=0.2976, R^{2}$ adjusted $=0.2414, \sigma^{2}=790.7322$

OLS Ordinary least squares, SE Standard error, VIF Variance inflation factor

* Statistical significance

best bandwidth, Gaussian function was chosen for this function based on the principle of minimum corrected Akaike information criterion $\left(A I C_{\mathrm{C}}\right)$. The parameters and fitting criterion of GWR models are shown in Tables 7 and 8 .

The results from the comparison of the OLS and the GWR approaches are displayed in Table 9. $A I C_{C}$ $\left(A I C_{C}=(2 \mathrm{k}-2 \mathrm{~L}) / n+2 \mathrm{k}(\mathrm{k}+1) /(n-\mathrm{k}-1)\right)$ is a criteria to evaluate the performance of statistical model; where $\mathrm{n}$ was the sample size, $\mathrm{k}$ repeated the concision and $\mathrm{L}$ repeated the accuracy of the model, meaning that if $A I C$ or $A I C_{C}$ was smaller, the model was better. The coefficient of determination $\left(R^{2}\right)$ and the degree-of-freedom adjusted coefficient of determination $\left(R^{2}\right.$ adjusted) assumed that the independent variable explains the variation in the dependent variable in the model. The model was better if the value of $R^{2}$ and $R^{2}$ adjusted was more approximate to zero. Mean square deviation $\left(\sigma^{2}\right)$ and residual sum of squares (RSS) were the deviation of variables. Concerning $P$. canaliculata, for OLS model, AIC was 306.0523 , $A I C_{\mathrm{C}}$ 308.7620, $R^{2}$ 0.0864, $R^{2}$ adjusted 0.0243 , and $\sigma^{2}$ 154.6894; while for GWR model, $A I C_{\mathrm{C}}$ was -30.9822 , $R^{2}$ 0.1307, $R^{2}$ adjusted 0.1345, RSS 0.4857, and $\sigma^{2}$ 0.0171 . The results showed that $A I C_{\mathrm{C}}, R^{2}, R^{2}$ adjusted and $\sigma^{2}$ in the GWR model were superior to the ones in the OLS model for $P$. canaliculata. With regard to rats, for OLS model, AIC was 529.8539, $A I C_{\mathrm{C}} 531.6039, R^{2}$ $0.2976, R^{2}$ adjusted 0.2414 , and $\sigma^{2} 790.7322$; while for GWR model, $R^{2}$ was $0.4411, R^{2}$ adjusted $0.3195, A I C_{\mathrm{C}}$
27.0182, RSS 3.1458, and $\sigma^{2}$ 0.0709. These also showed $A I C_{\mathrm{C}}, R^{2}, R^{2}$ adjusted and $\sigma^{2}$ in the GWR model were superior to those in the OLS model for rats. According to some authors [25], the GWR approach should be chosen, even though it was more complex, if the difference of $A I C$ between the two models were greater than 3. In our study, for both $P$. canaliculata and rats, $A I C_{C}$ in the GWR models was much larger than the value in the OLS models, indicating that the GWR model had more advantage in analysing spatial heterogeneity data. However, $R^{2}$ was not big in any of the two models, implying that the account of spatial variance that the models could explain was small, and the existing influence factor did not properly represent the spatial variance of infection rate data.

\section{Discussion}

In comparison with some other cities/provinces in China, e.g., Shenzhen [26] and Xiamen [27] and Hainan [28], the infection rates of $P$. canaliculata were lower than those from our findings, but they were higher in Dali [29] and Guangzhou [30]. However, our reported rate of infected rats was lower than those reported in Rio de Janeiro in Brazil [31], Canary Islands [32] and Nueva Ecija in the Philippines [33]; while it was higher than those found in Guangzhou [34] and Zhongshan [35] in China.

There was a significant difference in the infection rate between the different kinds of rats investigated, e.g., only one infected $R$. flavipectus was found, while there was

Table 7 Infection rates of Pomacea canaliculata with Angiostrongylus cantonensis using different variables estimated by GWR approach

\begin{tabular}{lllllll}
\hline Variable & Min & P25 & M & P75 & Max & SD \\
\hline Intercept & -0.0060 & 0.0807 & 0.0808 & 0.0888 & 0.0929 & 0.0381 \\
Seasons & 0.0070 & 0.0071 & 0.0075 & 0.0077 & 0.0113 & 0.0017 \\
Environmental types & -0.0074 & -0.0074 & -0.0065 & -0.0058 & 0.0037 & 0.0043 \\
Distance & -0.0308 & -0.3016 & -0.0293 & -0.0292 & -0.0031 & 0.0110 \\
Density & -0.0008 & 0.0021 & 0.0023 & 0.0027 & 0.0028 & 0.0014 \\
\hline
\end{tabular}

$R^{2}=0.1307, R^{2}$ adjusted $=0.1345, A / C_{C}=-30.9822$, RSS $=0.4857, \sigma^{2}=0.0171$

GWR: Geographically weighted regression; P25: The 25th percentile; M: Median; P75: The 75th percentile; SD: Standard deviation 
Table 8 Infection rates of rats with Angiostrongylus cantonensis using different variables estimated by GWR approach

\begin{tabular}{lllllll}
\hline Variable & Min & P25 & M & P75 & Max & 0.1290 \\
\hline Intercept & -0.2600 & -0.2580 & -0.2575 & 0.0395 & 0.1668 \\
Seasons & 0.0019 & 0.0020 & 0.0379 & 0.0382 & 0.0383 & 0.0179 \\
Environmental types & -0.0145 & 0.0266 & 0.0683 & 0.0684 & 0.0688 & 0.0303 \\
Distance & -0.0833 & -0.0831 & -0.0822 & -0.0309 & -0.0307 & 0.0246 \\
Density & -0.0560 & 0.0410 & 0.6670 & 0.6677 & 0.6703 & 0.3323 \\
\hline
\end{tabular}

$R^{2}=0.4411, R^{2}$ adjusted $=0.3195, A / C_{C}=27.0182, \mathrm{RSS}=3.1458, \sigma^{2}=0.0709$

GWR: Geographically weighted regression; P25: The 25th percentile; M: Median; P75: The 75th percentile; SD: Standard deviation

no infection in either $R$. losea or $S$. murinus. The reason could be attributed to the biological variation between different rat species, i.e. $R$. norvegicus and $R$. flavipectus live close to human dwellings and they were also known to prey on snails, while $R$. losea and $S$. murinus were field mice mainly feeding on plants [36], thereby lowering the expectation of infection.

The spatial distribution of infection rate of both $P$. canaliculata and the rat species showed spatial autocorrelation and aggregation. More so, positive $P$. canaliculata were mostly clustered in artificial channels near the villages, while the positive rats were more clustered in the places where the environment was what can be described as messy; consisting of garbage. Such places were always near human settlements, thus strengthening the probability for rats and molluscs to infect each other.

The result showed that GWR model was better than OLS model in terms of applicability, but the degree of fit of this model were not impressive. The possible reason was that our choice of factors that might influence infection was incomplete and some other possibly important factors, such as the normalized difference vegetation index (NDVI), temperature, rainfall, soil $\mathrm{pH}$ and socioeconomic status of the humans in the study area [37-40] were not part of our modelling. Such variables, particularly factors with potentially higher explanatory power need to be explored and included into spatial models in the future, in order to perfect further spatial models. We would also like to investigate different spatial scales [41], as well as improve the degree of fit of the models used by increasing sample sizes and the number of villages, with the expectation that these parameters might affect the finding.

Table 9 Comparison between OLS and GWR models

\begin{tabular}{llllll}
\hline Host & Approach & $\mathrm{AlC}_{C}$ & $R^{2}$ & $R^{2}$ adjusted & $\sigma^{2}$ \\
\hline Pomacea & OLS & 308.7620 & 0.0864 & 0.0243 & 154.6894 \\
canaliculata & GWR & -30.9822 & 0.1307 & 0.1345 & 0.0171 \\
Rat species & OLS & 531.6039 & 0.2976 & 0.2414 & 790.7322 \\
& GWR & 27.0182 & 0.4411 & 0.3195 & 0.0709 \\
\hline
\end{tabular}

OLS Ordinary least squares, GWR Geographically weighted regression, $A / C_{C}$ Corrected Akaike information criterion

\section{Conclusions}

The intermediate hosts and definitive hosts of $A$. cantonensis were widely distributed in Nanao Island and positive infection has also been found in the hosts. These findings indicate that there was a risk of angiostrongyliasis in this region of China, and intensive monitoring work on the hosts should be undertaken.

Our study also showed that there existed spatial correlation and spatial clusters in the spatial distribution of positive $P$. canaliculata and rats. The maximum radius of spatial cluster areas of positive rats was basically consistent with the rats' sphere of activity. More so, GWR model had advantage over OLS model in the spatial analysis of hosts of Angiostrongylus cantonensis.

\section{Additional file}

Additional file 1: Multilingual abstracts in the five official working languages of the United Nations. (PDF $261 \mathrm{~kb}$ )

\section{Abbreviations}

AlC: Akaike information criterion; $A / C_{C}$ : Corrected Akaike information criterion; GIS: Geographic Information System; GPS: Global positioning system; GWR: Geographically weighted regression; JB: Jarque-Bera; LLR: Log likelihood ratio; OLS: Ordinary least squares; RR: Relative risk; WHO: World Health Organization

\section{Acknowledgments}

The authors would like to express their deep appreciation to the staff of the Centres for Disease Control and Prevention of Nanao Island and Guangdong Province.

\section{Funding}

This study was funded by The Special Foundation of Basic Science and Technology Resources Survey of Ministry of Science and Technology of China (No. 2017FY101203), the National Key Research and Development Program of China (No. 2016YFC1202000, 2016YFC1202001), and the National Science and Technology Major Project of China (No. 2012ZX1004-220, 2008ZX1004-011)

Availability of data and materials

All data generated or analysed during this study and supporting the conclusions of this article are included within the article.

\section{Authors' contributions}

QH and ZY designed the study. QH, ZY, LH, YG, FY, LQ, QZ and GL collected the samples and data. QH performed the statistical analysis and wrote the paper. LS, XS, ZD and CY reviewed and coordinated the manuscript. All the authors have read and approved the final manuscript. 


\section{Ethics approval and consent to participate}

No specific permits were required for this study. The study did not involve endangered or protected species.

\section{Consent for publication}

Not applicable.

\section{Competing interests}

The authors declare that they have no competing interests.

\section{Author details}

${ }^{1}$ National Institute of Parasitic Diseases, Chinese Center for Disease Control and Prevention; Chinese Center for Tropical Diseases Research, Shanghai 200025, China. ${ }^{2}$ WHO Collaborating Centre for Tropical Diseases; National Center for International Research on Tropical Diseases, Ministry of Science and Technology, Shanghai 200025, China. ${ }^{3}$ Key Laboratory of Parasite and Vector Biology, Ministry of Health, Shanghai 200025, China. ${ }^{4}$ Centre for Disease Control and Prevention of Guangdong Province, Guangzhou 510300, China. ${ }^{5}$ Shanghai Medical College, Fudan University, Shanghai 200032, China.

Received: 2 May 2018 Accepted: 4 September 2018

\section{Published online: 15 October 2018}

\section{References}

1. Barratt J, Chan D, Sandaradura I, Malik R, Spielman D, Lee R, et al. Angiostrongylus cantonensis: a review of its distribution, molecular biology and clinical significance as a human pathogen. Parasitology. 2016;143:1087-118.

2. Vitta A, Polseela R, Nateeworanart S, Tattiyapong M. Survey of Angiostrongylus cantonensis in rats and giant African land snails in Phitsanulok province, Thailand. Asian Pac J Trop Med. 2011:4:597-9.

3. Graeff-Teixeira C, Da SA, Yoshimura K. Update on eosinophilic meningoencephalitis and its clinical relevance. Clin Microbiol Rev. 2009;22:322-48.

4. Yang TB, Wu ZD, Lun ZR. The apple snail Pomacea canaliculata, a novel vector of the rat lungworm, Angiostrongylus cantonensis: its introduction, spread, and control in China. Hawaii J Med Public Health. 2013;72:23-5.

5. LV S, Zhang Y, Steinmann P, Zhou XN. Emerging angiostrongyliasis in mainland China. Emerg Infect Dis. 2008;14:161-4.

6. Song L, Wang X, Yang Z, Lv Z, Wu Z. Angiostrongylus cantonensis in the vector snails Pomacea canaliculata and Achatina fulica in China: a metaanalysis. Parasitol Res. 2016;115:913-23.

7. Lv S, Zhang Y, Liu HX, Hu L, Yang K, Steinmann P, et al. Invasive snails and an emerging infectious disease: results from the first national survey on Angiostrongylus cantonensis in China. PLoS Negl Trop Dis. 2009:3:e368.

8. Guo YH, LV S, Gu WB, Liu HX, Wu Y, Zhang Y. Investigation on the species distribution and infection status of host snails of Angiostrongylus cantonensis in Shanghai. Chin J Parasitol Parasit Dis. 2014;32:455-8 (in Chinese).

9. Chen M, Chen J, Chen S, Huang D, Ai L, Zhang R. Development of lateral flow immunoassay for antigen detection in human Angiostrongylus cantonensis infection. Korean J Parasitol. 2016:54:375-80.

10. Floch HA, Courdurier J, Jacobi JC. Contribution to the study of the geographical distribution of Angiostrongylus cantonensis. Bull Soc Pathol Exot Filiales. 1966;59:365-71.

11. Stensgaard AS, Saarnak CF, Utzinger J, Vounatsou P, Simoonga C, Mushinge $G$, et al. Virtual globes and geospatial health: the potential of new tools in the management and control of vector-borne diseases. Geospat Health. 2009:3:127-41

12. Lyseen AK, Nohr C, Sorensen EM, Gudes O, Geraghty EM, Shaw NT, et al. A review and framework for categorizing current research and development in health related geographical information systems (GIS) studies. Yearb Med Inform. 2014;9:110-24.

13. Zhang Y, Lv S, Yang K, Liu HX, Hu L, Li LS, et al. The first national survey on natural nidi of Angiostrongylus cantonensis in China. Chin J Parasitol Parasit Dis. 2009:27:508-512. (in Chinese).

14. Deng Z, Zhang Q, Huang S, Jones JL. First provincial survey of Angiostrongylus cantonensis in Guangdong Province, China. Tropical Med Int Health. 2012;17:119-22.

15. Liu HX, Zhang Y, Lv S, Zhu D, Ang XH, Hu L, et al. A comparative study of three methods in detecting Angiostrongylus cantonensis larvae in lung tissue of Pomacea canaliculata. Chin J Parasitol Parasit Dis. 2007:25:53-56. (in Chinese).
16. Tsai PJ, Lin ML, Chu CM, Perng CH. Spatial autocorrelation analysis of health care hotspots in Taiwan in 2006. BMC Public Health. 2009:9:464.

17. Chen Z, Zhou XN, Yang K, Wang XH, Yao ZQ, Wang TP, et al. Strategy formulation for schistosomiasis japonica control in different environmental settings supported by spatial analysis: a case study from China. Geospat Health. 2007:1:223-31.

18. Zhao F, Zhu R, Zhang LJ, Geng YJ, Huang DN, Liu JP, et al. Application of saTScan in detection of schistosomiasis clusters in marshland and lake areas. Chin J Parasitol Parasit Dis. 2011;23:28-31. (in Chinese).

19. Bosomprah S, Dotse-Gborgbortsi W, Aboagye P, Matthews Z. Use of a spatial scan statistic to identify clusters of births occurring outside Ghanaian health facilities for targeted intervention. Int J Gynaecol Obstet. 2016;135:221-4.

20. Lin PS, Kung YH, Clayton M. Spatial scan statistics for detection of multiple clusters with arbitrary shapes. Biometrics. 2016;72:1226-34.

21. Culpepper SA. Using the criterion-predictor factor model to compute the probability of detecting prediction bias with ordinary least squares regression. Psychometrika. 2012;77:561-80.

22. Siordia C, Saenz J, Tom SE. An introduction to macro- level spatial nonstationarity: a geographically weighted regression analysis ofdiabetes and poverty. Human Geogr. 2012;6:5-13.

23. Duarte-Cunha M, Almeida AS, Cunha GM, Souza-Santos R. Geographic weighted regression: applicability to epidemiological studies of leprosy. Rev Soc Bras Med Trop. 2016:49:74-82.

24. Luo J, Du P, Samat A, Xia J, Che M, Xue Z. Spatiotemporal pattern of PM2.5 concentrations in China's mainland and analysis of its influencing factors using geographically weighted regression. Sci Rep. 2017;7:40607.

25. Thapa RB, Estoque RC. Geographically weighted regression in geospatial analysis. In: Murayama Y, editor. Progress in geospatial analysis. Tokyo: Springer Japan; 2012. p. 85-96.

26. Zhang RL, Chen MX, Gao ST, Geng YJ, Huang DN, Liu JP, et al. Enzootic angiostrongyliasis in Shenzhen, China. Emerg Infect Dis. 2008;14:1955-6.

27. Li LS, Zhang RY, Fang YY, Ouyang $R$, Xie HG, Jiang DW, et al. Prevalence of Angiostrongylus cantonensis infection in snails for sale in Fuzhou and Xiamen. Chin J Parasitol Parasit Dis. 2013:31:464-466.(in Chinese).

28. Hu X, Du J, Tong C, Wang S, Liu J, Li Y, et al. Epidemic status of Angiostrongylus cantonensis in Hainan island, China. Asian Pac J Trop Med. 2011:275-7

29. Zhang XX, Cui LY, Cao SZ, Wang F, Li KH, Wang JY, et al. Preliminary survey on the host of Angiostrongylus cantonensis in three plateau lakes of Yunnan Province. Chin J Parasitol Parasit Dis 2014:32:139-142, 147. (in Chinese).

30. Chen CX, He HF, Yin Z, Zhou JH, Li SQ, Li FH, et al. Investigation on snails Achatina fulica and Pomacea canaliculata infected with Angiostrongylus cantonensis in Panyu region of Guangzhou City. Chin J Schisto Control 2012;24:336-338. (in Chinese).

31. Simoes RO, Maldonado JA, Olifiers N, Garcia JS, Bertolino AV, Luque JL. A longitudinal study of Angiostrongylus cantonensis in an urban population of Rattus norvegicus in Brazil: the influences of seasonality and host features on the pattern of infection. Parasit Vectors. 2014;7:100.

32. Martin-Alonso A, Foronda P, Quispe-Ricalde MA, Feliu C, Valladares B. Seroprevalence of Angiostrongylus cantonensis in wild rodents from the Canary Islands. PLoS One. 2011;6:e27747.

33. Tujan MA, Fontanilla IK, Paller VG. Vectors and spatial patterns of Angiostrongylus cantonensis in selected rice-farming villages of Munoz, Nueva Ecija, Philippines. J Parasitol Res. 2016;2016:3085639.

34. Yang $\mathrm{X}, \mathrm{Qu} Z$, He H, Zheng $\mathrm{X}$, He A, Wu Y, et al. Enzootic angiostrongyliasis in Guangzhou, China, 2008-2010. Am J Trop Med Hyg. 2012;86:846-9.

35. Pan B, Wu J, Ruan CW, Liang WJ, Deng ZH, Zhang QM, et al. Investigation on Angiostrongylus cantonensis infection in rodents in Guangdong Province. China Chin J Parasitol Parasit Dis 2011;29:289-292.(in Chinese).

36. Chen D, Zhang Y, Shen H, Wei Y, Huang D, Tan Q, et al. Epidemiological survey of Angiostrongylus cantonensis in the west-central region of Guangdong Province, China. Parasitol Res. 2011;109:305-14.

37. Byers JE, McDowell WG, Dodd SR, Haynie RS, Pintor LM, Wilde SB. Climate and $\mathrm{pH}$ predict the potential range of the invasive apple snail (Pomacea insularum) in the southeastern United States. PLoS One. 2013;8:e56812.

38. Ishii Al. Effects of temperature on the larval development of Angiostrongylus cantonensis in the intermediate host, Biomphalaria glabrata. Z Parasitenkd. 1984;70:375-9.

39. Tolnai Z, Szell Z, Sreter T. Environmental determinants of the spatial distribution of Angiostrongylus vasorum, Crenosoma vulpis and Eucoleus aerophilus in Hungary. Vet Parasitol. 2015;207:355-8. 
40. Aufderheide J, Warbritton R, Pounds N, File-Emperador S, Staples C, Caspers $\mathrm{N}$, et al. Effects of husbandry parameters on the life-history traits of the apple snail, Marisa cornuarietis: effects of temperature, photoperiod, and population density. Invertebr Biol. 2006;125:9-20.

41. Xu M, Fang M, Yang Y, Dick JT, Song H, Luo D, et al. Spatial variation in adult sex ratio across multiple scales in the invasive golden apple snail, Pomacea canaliculata. Ecol Evol. 2016;6:2308-17.

Ready to submit your research? Choose BMC and benefit from:

- fast, convenient online submission

- thorough peer review by experienced researchers in your field

- rapid publication on acceptance

- support for research data, including large and complex data types

- gold Open Access which fosters wider collaboration and increased citations

- maximum visibility for your research: over $100 \mathrm{M}$ website views per year

At $\mathrm{BMC}$, research is always in progress.

Learn more biomedcentral.com/submissions 